\title{
Elle est morte
}

Citation : CMAJ 2021 November 8;193:E1704. doi : 10.1503/cmaj.211127-f

Voir la version anglaise de l'article ici : www.cmaj.ca/lookup/doi/10.1503/cmaj.211127

L e moniteur cardiaque lance un son strident, puis montre un tracé continu. Elle est morte. Je reste là, abattu, tête baissée. Mes filles sont en pleurs.

Une infirmière se précipite dans la chambre, suivie d'un aumônier et d'une travailleuse sociale. Ils cherchent à adoucir notre peine. «Voulez-vous dire une prière? » "Voudriez-vous que je vous apporte quelque chose? » Elle est partie vers un monde meilleur. » Leurs mots m'agressent. "Non, je ne veux pas de prière. » "Non, je n'ai besoin de rien. " "Non, elle n'est pas partie vers un monde meilleur. » On frappe à la porte, c'est un médecin stagiaire. Sarrau taché, allure débraillée, odeur de vieux café. Il vient confirmer le décès, comme l'exige la loi. Il s'approche du lit, écoute le cœur pendant 1 minute, peut-être 2 . Il cherche le pouls. Est-ce son premier décès? Il écrit dans sa main (l'heure du décès?), puis fait cliquer son stylo. Il clique et clique encore. La sueur au front, il jette un regard sur ma femme : "Voudriez-vous une autopsie? » Une autopsie, une dissection du corps pour déterminer la cause du décès. "Non, merci ». Nous connaissons la cause; nous voulons qu'elle rentre chez nous. La sortir de cet hôpital de Los Angeles pour la ramener à un crématorium à Phoenix. L'infirmière s'approche, me prend doucement le bras: "Vous pouvez rester avec elle aussi longtemps que vous voulez. " Je voudrais rester avec elle 30 ans de plus.

Nous nous attardons près du lit, à la toucher, à la caresser, à l'embrasser. Sa peau est fraîche, presque froide, la chaleur l'ayant déjà quittée. Je prends un pas de recul et regarde la chambre. C'est trop petit ici. « Nous devrions partir maintenant. » Mes filles me regardent dans les yeux. J'ai honte. Mais pourquoi donc est-ce que je voudrais m'en aller? Je ne la reverrai plus jamais. Je leur dis que nous restons.

Je sors de la chambre et m'appuie sur une chaise. L'infirmière approche. "Avez-vous pris des arrangements pour le corps? „ Le corps. Pas ma femme, le corps. Je n'ai pas fait d'arrangements; je ne pensais pas qu'elle mourrait, pas si tôt. Les médecins ont dit qu'elle s'en sortirait, qu'elle rentrerait à la maison. Ils l'ont promis. Mais comment ai-je pu ne pas savoir? Défaillance du cœur, des poumons et des reins. Désactivation du défibrillateur. Comment ai-je pu ne pas savoir? " Je n'ai pas fait d'arrangements. » Je me sens idiot, pris au dépourvu. L'infirmière fait signe à la travailleuse sociale. Elle suggère un salon funéraire des environs. "Ils organiseront le retour de la dépouille de votre femme, qui pourra alors être enterrée ou incinérée. » La dépouille? C'est donc ce qu'elle est maintenant, une dépouille? «Nous les appellerons et ferons le nécessaire. Ils auront besoin d'une carte de crédit; vous pourrez la présenter à leur arrivée. » Dépouille, carte de crédit... Son décès s'est transformé en transaction.

Je reviens à la chambre. Ma fille, la plus jeune, est en émoi : elle craint qu'on manque de respect à sa mère à la morgue. Je lui dis qu'ils veilleront bien sur elle, mais en fait je ne le sais pas. Qui le sait, d'ailleurs? Le responsable des pompes funèbres arrive. Il affiche un air solennel et sent l'eau de Cologne. Il parle, mais je n'entends pas. Il met un stylo dans ma main, je signe des papiers que je ne lis pas. Je coche la case «veuf». Pour le retour, on s'occupera de mettre son corps sur un vol commercial. Elle sera dans la soute à bagages. Dans un cercueil. Un bagage en forme de cercueil. "Nous vous donnerons dix ou douze certificats de décès, vous en aurez besoin. C'est plus facile de se les procurer maintenant au lieu d'attendre. „ Dix certificats? Ou douze? Chaque fois que j'en regarderai un, elle mourra à nouveau. Je n'en veux pas plus qu'il faut. "Restez avec elle aussi longtemps que vous voulez. Nous récupérerons le corps plus tard en soirée. Elle sera dans l'avion en fin de journée demain. " Je le remercie. Il me donne l'accolade, en laissant son odeur d'eau de Cologne sur mes vêtements.

Je ferme les yeux, perdu, confus. Je suis incapable de raisonner, le brouillard de mes pensées se désagrège. Je vais à la salle de bains des visiteurs, verrouille la porte, mets mes mains sur le lavabo, fixe le miroir. Je regarde ma tête d'un côté, de l'autre. Cheveux en bataille, sourcils froncés, yeux rouges. Vaincu. Je pleure, encore et encore, vidant mon corps de tout son sel. Bref soulagement. Puis je pleure encore. On cogne à la porte. Mes filles; elles sont prêtes à partir. J'ouvre la porte. Les lampes fluorescentes du corridor m'éblouissent. Je ferme presque les yeux. Je vois le mari d'une femme qui est à l'unité de soins intensifs, près d'où était ma femme. Était, au passé. Il m'approche, ses lèvres remuent : "Comment va votre femme? » Je m'effondre contre le mur. "Elle est morte. " Mes filles me prennent par le bras. Nous marchons vers l'ascenseur. Pour une dernière fois, je remplis mes poumons de l'air qu'elle a respiré. La porte s'entrouvre, et nous descendons. Le monde n'est plus pareil. Elle est morte.

\section{Paul C. Rousseau MD}

Soins palliatifs, Charleston, Caroline du Sud

Cet article a été révisé par des pairs.

Il s'agit d'une histoire vraie.

Propriété intellectuelle du contenu : II s'agit d'un article en libre accès distribué conformément aux modalités de la licence Creative Commons Attribution (CC BY-NC-ND 4.0), qui permet l'utilisation, la diffusion et la reproduction de tout médium à la condition que la publication originale soit adéquatement citée, que l'utilisation se fasse à des fins non commerciales (c.-à-d., recherche ou éducation) et qu'aucune modification ni adaptation n'y soit apportée. Voir : https://creativecommons.org/licenses/by -nc-nd/4.0/deed.fr. 